\title{
Cross-Curriculum Teaching
}

\author{
Yavor Georgiev \\ Instructor of Spanish ALL Department AUBG Bulgaria, Blagoevgrad \\ YGueorguiev@aubg.bg
}

\begin{abstract}
This article presents the Interdisciplinary collaboration and its potential and value for the modern education process. It also shares several examples from author's experience in Teaching Foreign Languages and further conclusions about cross-disciplinary work. Future is hold by those who are prepared to work in team and to create new products putting together knowledge from different scientific fields. This approach is one of the major challenges for the educators today, and it's a fundamental step in the process of creation of future leaders. A few years ago the author got a chance to meet a famous scientist and explorer who hasopened his eyes towards this approach with several examples of collaborative work. Before that, the Interdisciplinary teaching, its potential and value for the contemporary education were no men's land for the author.Since then, he has been keeping his eyes open to everything surrounding his lifeand he has tracked a good amount of examples of cross-disciplinary work. Now he realizes this is one of the major challenges for the educators today, and it's a fundamental step in the process of creation of future leaders which we're attempting to develop.
\end{abstract}

Keywords: Cross curriculum, teaching, education, foreign languages

\section{Introduction}

Definition\& basic concepts: The roots of this new tendency could be found back in the 80s. A basic definition is offered by Humphreys (Humphreys, Post, and Ellis, 1981) when he states, "An integrated study is one in which children broadly explore knowledge in various subjects related to certain aspects of their environment". All kind of definitions support the view that integrated curriculum is an educational approach that prepares young people for lifelong learning. There is strong belief that schools must look at education as a process for developing abilities required by life in the twenty-first century, rather than discrete, departmentalized subject matter. The interdisciplinary curriculum should be a combination of subjects, an emphasis on projects, sources that go beyond textbooks, relationships among concepts, thematic units as organizing principles, flexible schedules, and flexible student groupings. In the 90s Content and Language Integrated Learning (CLIL) was documented for first time by the European Platform EUROCLIC (http://www.europeesplatform.nl/sf.mcgi?id=96), and was the first significant achievement in this area. They based their theory on the fact that learning a language is a cognitive and natural process, and that a foreign language can be taught through many academic disciplines, different from the language per se (Marsh, 2002). It's a process where "the FL Teaching is not the goal of one and the same subject, but of the whole academic curriculum" (Baeten, 2009). The greatest benefit of the CLIL approach is that a student stays in contact with the target language much longer, and the most important, its use is contextualized, i.e. it is given a real sense. In the practice, this means that subjects like Biology, Geography and Mathematics, for example, can be taught in the target language, broadening this way the communicative contexts. Actually, there are many schools around the world that have implemented this approach in their curriculum. For instance, in Bulgaria there are the popular Bilingual High schools. Of course, this methodology requires thatteachers from different disciplines collaborate much closer than usual, offering students a bunch of logically related activities which allowthem to catch up easily with the material and to connect the logical dots between the variety of academic disciplines.

The CLIL is still an innovative and challenging process, but it was just the beginning of something that's much bigger today: the Interdisciplinarycollaboration. What started out like teaching integrated contents through different subjects, now is a cognitive approach where knowledge from different fields is put together in order to create new products. We have gone about as far as we can go with isolated instruction and learning. Many teachers around the world are still stuck at their specific fields and they are having hard time finding other ways and new discoveries. This is outdated. While it may have served the purpose for the older generations, it does not meet "the deeper learning needs of people today and tomorrow". (Johnson, 2013). Students today have to learn how to be great contributors tomorrow. Deeper learning can be accelerated by consolidating teacher efforts and combining relevant contents, in 
effect, opening new spillways of knowledge. It's absolutely impossible to educate a new collaborative generation of people without the clear conviction of the educators. The biggest challenge for the teachers is that we have to show students how to work in team, how to share and how to use the received knowledge from their colleagues. A translation of all these words to some simple examples would be to get back to the Bilingual High-schools scenario, where, for example, students are given the task to create a resume in Spanish of several definitions and formulas in Chemistry, and after that to create HTML version of this information. What do we need for this? On first place, a good team of teachers in Spanish, Chemistry and IT, who are flexible enough so the Syllabus of each one of them can fit into the learning methodology of their colleagues.

Cross-curricular teaching involves a conscious effort to apply knowledge, principles, and/or values to more than one academic discipline simultaneously. The disciplines may be related through a central theme, issue, problem, process, topic, or experience (Jacobs, 1989). The organizational structure of interdisciplinary collaboration is called a theme, thematic unit, or unit, which is a framework with goals/outcomes that specify what students are expected to learn as a result of the experiences and lessons that are a part of the unit. Interdisciplinary teaching is often seen as a way to address some of the recurring problems in education, such as fragmentation and isolated skill instruction. It is seen as a way to support goals such as transfer of learning, teaching students to think and reason, and providing a curriculum more relevant to students. This new approach also corresponds perfectly to 4Cs of the 21st century education: critical thinking and problem solving; communication, collaboration; and creativity and innovation.

\section{Examples from every-day life}

If we take apart the raw theory about this approach and we take a look at the myriad of events and news from our everyday life, we can easily find many examples of this collaborative kind of thinking and work.

- The most recent one is literally from yesterday, April 4th 2013. The Facebook owner, Mark Zuckerberg, announced company's new development called Facebook Home. This software is being developed in "a partnership with the handset manufacturer, HTC, which has developed a phone with the software built into it." (Caroll, 2013). Even the biggest companies don't work alone, but in collaboration with others. This way, they offer a new competitive product.

- We all have used at one point Google Translate, and we all know it's not what it should be. Its inaccuracy and inadequacy in translation is disappointing. However, there are several companies working on the main goal in translation: that a machine is able to translate the adequate meaning by doing a lightning fast analysis of information and language codes as the real human brain can do. Not an easy job, indeed. However, big achievements have been made. Natural Language Processing (NLP) is a scientific field where many linguists, computer engineers, etc. have joined their efforts. Fun Gram KB is just a good example of team work among many others (http://carlosgonzalezvergara.weebly.com/fungramkb.html)

- Convinced that future will be hold by those people who manage to work in team sharing their knowledge from different social and scientific fields into a new product, the author of this article realized that the first goal of the teacher today is to educate our students to this model, but also to convince other teachersto it.

\section{Ongoing Projects}

On Spring semester 2013 the author initiated a project between MLL<->HTY and COS Department of AUBG for a new generation tourist guide of Bulgaria in Spanish. This work requires the knowledge, the experience, the correct data and the IT skills of a team of researchers. Noone of them can reach to a decent result in this aspect by working on their own. This is still an ongoing Project, so results will be revealed later. Another ongoing work of interdisciplinary collaboration is the one proposed to the students from MLL 256 Intermediate Spanish II course, spring 2013. It started as a routine in-class activity. The majority of the FLL materials available today are based on the task-based approach. All the language skills taught and learned through each chapter, gravitate around one main activity that pretends to put students in a situation closer to the real life. Unfortunately, there is no tool still that can substitute the real communicative environment that is why teachers should be as creative as possible. At the end of Chapter 6 of Gente 2 (B2) book, the author of this project proposed a creation of a video material in Spanish, which talks about the AUBG life of people from different nationalities. The idea was polished 
with the help of the students. Besides the cross-curricular approach, this activity actually, fits many goals at once: to offer students a real life situation, to make a product, which can be, used effectively for the needs of the AUBG Focus 2017 campaign. In addition, as a strong believer in the interdisciplinary approach, the author considers this video shooting a great opportunity where students can apply the knowledge they acquired from different fields into one new product. This mix of MLL and JMC skills results in a really motivating and useful effort. MLL Spanish skills are being used when preparing the spoken text, or its translation in Spanish. Everything has to be correct in terms of Grammar and Semantic. JMC skills like shooting audio \& video, camera position, lights, focus, effects, mastering, etc. are being used also during the whole process. At the moment of this conference the author and his studentsmanaged to record the video \& audio, to edit the raw material, they did the mastering and added subtitles in the target language. Video can be watched by visiting the following web address: http://youtu.be/kXDXDwiswuE

The team encountered a problem when synchronizing subtitles in YouTube and currently is working to fix it. In any case, giving the fact that the product is almost completed, the author would conclude in favor of his main thesis showed in this paper, that it is clear that people only from one discipline couldn't have done this. These are the conclusions made until this moment:

- When the director of the project is not sure, what exactly the final result should look like that can be disappointing and demotivating for the students.

- Since there is no previous experience with similar activities, all the members of the team have to be prepared to learn new things on every single step, and have to be as flexible as they can, since many times an improvisation at the moment could be necessary. Otherwise, the work gets chaotic and pointless.

- An appropriate distribution of duties is required, a small groups where formed, one in charge of the technical aspect (camera, microphones, etc.), others are organizers who have to meet with several students trying to convince to take part in the video, and one more: for the script.

- Making a closed group in Facebook makes wonders. It's the most popular social network, people are constantly there and it's easier to see them giving ideas than when in class.

- The use of social networking leans to much better participation and communication mainly on the target language: an excellent and motivating practice.

\section{References}

Baeten-Beardsmore, H. (2009). CLIL debate, IATEFL

Caroll, R. (2013). Zuckerberg eyes Android takeover with 'best version of Facebook there is, The Gardian 'http://www.guardian.co.uk/technology/2013/apr/04/mark-zuckerberg-facebook-homeandroid

Humphreys, A., Post, T. \& Ellis, A. (1981). Interdisciplinary Methods: A Thematic Approach. Santa Monica, CA: Goodyear Publishing Company, p.11

Jacobs, H. H. (1989). Interdisciplinary Curriculum: Design and Implementation. Alexandria, VA: Association for Supervision and Curriculum Development

Johnson, B. (2013). http://www.edutopia.org/blog/cross-curricular-teaching-deeper-learning-benjohnson

Marsh, D. (2002). CLIL/EMILE- The European Dimension: Actions, Trends and Foresight Potential Public Services Contract DG EAC: European Commission 